\title{
Laboratory tests and compliance of dermatologic outpatients
}

\section{[version 1; peer review: 2 approved]}

\author{
Won Ung Shin1, Yoo Sang Baek1, Tom Joonhwan Kim², Chil Hwan Oh¹, \\ Jaehwan Kim³
}

${ }^{1}$ Department of Dermatology, College of Medicine, Korea University, Seoul, South Korea

${ }^{2}$ Robert H. Smith School of Business, University of Maryland, College Park, MD 20742, USA

${ }^{3}$ Laboratory for Investigative Dermatology, The Rockefeller University, New York, NY 10065, USA

V1 First published: 07 Oct 2013, 2:206

https://doi.org/10.12688/f1000research.2-206.v1

Latest published: 07 Oct 2013, 2:206

https://doi.org/10.12688/f1000research.2-206.v1

\section{Abstract}

Laboratory tests, including blood tests and urine analysis, are frequently performed in the dermatology outpatient clinic, but doctors often do not consider the cognitive or psychological effect of the examinations. Based on terror management theory, we hypothesized that performing laboratory tests increases the patient's fear of mortality, and therefore has a positive effect on the patient's attitude toward the doctor's recommendations and willingness to accept them. The study employed a single factor between-subjects design, using a questionnaire completed by the patients. One group consisted of patients who had undergone laboratory tests 1 week before the survey, and the other group consisted of patients who had not undergone a laboratory test. Although the differences between two groups were not statistically significant, the patients who had laboratory tests had tendency to show even lower positive attitude toward the doctor's recommendations and less intention to follow the recommendations. In contrast to our hypothesis, performing laboratory tests does not subliminally increase patients' fears or anxieties about their disease or their compliance with doctors' recommendations.

Keywords

Laboratory test; Compliance; Dermatologic Outpatients

\section{Open Peer Review \\ Approval Status \\ 1 \\ 2 \\ version 1 \\ 07 Oct 2013

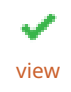 \\ view}

1. Mohamed Badawy Hassan Tawfik Abdel-

Naser, Ain Shams University, Cairo, Egypt

2. Roberto Arenas (iD), Hospital General Dr

Manuel Gea Gonzalez, Tlalpan, Mexico

Any reports and responses or comments on the article can be found at the end of the article. 
Corresponding author: Jaehwan Kim (Jaehwan.Kim@rockefeller.edu)

Competing interests: No competing interests were disclosed.

Grant information: The author(s) declared that no grants were involved in supporting this work.

Copyright: $\odot 2013$ Shin WU et al. This is an open access article distributed under the terms of the Creative Commons Attribution License, which permits unrestricted use, distribution, and reproduction in any medium, provided the original work is properly cited. Data associated with the article are available under the terms of the Creative Commons Zero "No rights reserved" data waiver (CC0 1.0 Public domain dedication).

How to cite this article: Shin WU, Baek YS, Kim TJ et al. Laboratory tests and compliance of dermatologic outpatients [version 1; peer review: 2 approved] F1000Research 2013, 2:206 https://doi.org/10.12688/f1000research.2-206.v1

First published: 07 Oct 2013, 2:206 https://doi.org/10.12688/f1000research.2-206.v1 


\section{Introduction}

Compliance in health care has been defined as the extent to which a person's behavior coincides with health-related advice ${ }^{1}$. Numerous factors have been suggested to influence patient compliance, including individual characteristics, illness type and severity, medication complexity, and emotional status ${ }^{2}$. Adherence to treatment of the patients with several chronic diseases such as diabetes, glaucoma, multiple sclerosis and psychological problems was studied in various trials that emphasized the influence of psychological components ${ }^{3-5}$. However, most surveys of patient compliance in dermatology have focused on dermatological diseases and types of treatment ${ }^{6,7}$.

In this study, we hypothesized that the examinations performed in dermatologic clinics may affect patient compliance. In a dermatologic clinic, laboratory tests such as blood and urine tests are one of the main examinations along with skin biopsy. Laboratory tests are usually performed to diagnose systemic disease associated with skin lesions or to monitor patient's vital organ functions. Dermatologists usually focus on the results of laboratory tests without considering the psychological impact of the tests.

One of the studies on patient compliance in dermatology by Kim et al. ${ }^{8}$ examined the psychological influence of skin biopsy based on terror management theory (TMT). TMT proposes that awareness of death is a critical motivating force in human behavior' ${ }^{9}$. The theory states that people cope with fear against death through sustaining faith in cultural worldviews, and get self-esteem by pursuing to the standards of values provided by the cultural worldviews. A cultural world-view means "humanly created and transmitted beliefs about the nature of the reality shared by groups of individuals ${ }^{10}$. By following cultural values and engaging in culturally prescribed behaviors, one can pursue the meaning of existence and perpetuity ${ }^{10-12}$. The study by Kim et al. ${ }^{8}$ showed that receiving a skin biopsy led patients to have a greater tendency to follow a doctor's recommendations.

Most patients visiting dermatologic clinics are not concerned about systemic disease, vital organ dysfunction or mortality, unless they have chronic skin diseases or skin cancers. However, we hypothesized that performing laboratory tests subliminally reminds patients of systemic disease, vital organ dysfunction or mortality. Based on TMT, laboratory test could increase patients' death-related thinking and might increase their willingness to accept the recommendations of doctors, whose authority is acknowledged by culture. We investigated the relationship between performing laboratory tests and acceptance of a doctor's recommendations. In addition, the effects of the patient's trust toward doctors, authoritarian personality, and mood on medical compliance were also studied.

\section{Material and methods}

\section{Participants}

Among the patients that attended the dermatology clinic in Korea University Guro Hospital (Seoul, South Korea) between 1 July 2011 and 31 August 2011, a total of 100 first time visitors were requested to fill out the survey. Written informed consent was obtained from all participants in this study. A total of 45 male patients and 55 female patients were included in the study. A group of 50 patients underwent laboratory tests, while the other group of 50 patients did not have any laboratory tests. Laboratory tests included urine analysis and blood tests such as: complete blood count, liver function test, blood urea nitrogen analysis, and creatinine analysis. We included patients aged between 18 and 65 years old and excluded patients who had a history of psychological disorders, -had undergone other tests besides the above mentioned laboratory tests (such as a skin biopsy or a patch test), or who had undergone procedures such as laser treatment or cryotherapy.

\section{Survey}

The patients were asked to complete the survey within two weeks on their second visit to the clinic. The survey measured their trust towards doctors, authoritarian personality, current mood, attitude toward the doctor's recommendation, and intention to follow the recommendations. Participants were asked to indicate the extent to which they agree with a given statement on the survey by using a seven-point scale (strongly disagree, disagree, disagree somewhat, undecided, agree somewhat, agree, strongly agree). The full questionnaire is available as supporting data.

\section{Trust toward doctors}

Several studies have measured patient's trust in physicians using scales $^{13,14}$, and we modified those scales so they included 5 statements to measure trust towards doctors: "I believe that doctors perform: 1. Perform only medically necessary tests and procedures, 2. keep personally sensitive medical information private, 3 . perform necessary medical tests and procedures regardless of cost, 4. put my health and well-being above keeping down the health plan's cost (reverse scale), and 5. I trust the doctors' judgment when it comes to my medical care". In case of fourth state reverse scale was used, and average of patients' scale to these five questions was used.

\section{Authoritarian personality}

The grades of authoritarianism are 1 . adheres strongly to conventional moral values, 2. submissive to established authorities, and 3. willingness to be aggressive toward others if they are perceived as unconventional or threatening ${ }^{15}$. We hypothesized that the grade of authoritarian personality, together with the amount of trust towards doctors, might influences patients compliance with medical treatment. K. Min ${ }^{16}$ has developed standards for measuring Korean authoritarian personality grades, and the scale consist of 35 questions measuring conventionalism, authoritarian obedience, authoritarian aggressiveness, anti-introspectionism, stereotypical thinking, belief in power, cynicism, and sexism. Based on this scale, we randomly selected four items measuring authoritarian obedience, and average of patients' scales to these questions was used.

\section{Mood}

We considered that the mood of the patients during the survey was a potential confounder affecting patient compliance, and patients who underwent laboratory tests might feel differently compared to patients who did not. To measure patient mood, they were asked to answer the twenty questions measuring their current mood (PANAS-X(17)). This measurement consists of 10 positive feelings (active, alert, attentive, determined, enthusiastic, excited, inspired, interested, proud, strong) and 10 negative feelings (afraid, scared, nervous, jittery, irritable, hostile, guilty, ashamed, upset, distressed). Average of patients' scales to these twenty questions was used. 


\section{Attitude toward recommendation and intention to accept recommendations}

In the last part of the survey, patients read a scenario: "You have a severe and chronic skin disease, and your doctor recommends a newly developed treatment method for you. He tells you that this method can reduce treatment time, but it is more expensive than traditional treatment and safety is not fully guaranteed". After reading the scenario, the attitude toward the scenario was measured using three 7 scale questions that were used in previous marketing studies ${ }^{18}$. Average of patients' scales to these three questions was used.

As another dependent variable, the intention to accept recommendations was measured by answering the following two statements: "I will follow the recommendations of the doctor," and "There is a possibility of following recommendations of the doctor". The patients responded on a seven-point scale (strongly disagree, disagree, disagree somewhat, undecided, agree somewhat, agree, strongly agree). Average of patients' scales to these two questions was used.

\section{Statistical analysis}

SPSS software (Version 15.00, SPSS Inc, Chicago, IL, USA) was used to conduct the statistical analyses and $p$-value less than 0.05 was considered to be statistically significant. Data analysis consisted of the unpaired $t$-test, two-way analysis of variance (ANOVA) test and correlation analysis.

\section{Results}

\section{Demographic analysis}

Forty five (45\%) male patients and fifty five $(55 \%)$ female patients completed the survey. Each group (laboratory tests vs. no laboratory test) consisted of 50 patients, and the mean age of the groups was 37.42 years for the laboratory test group (range 19-65) and 39.56 years for the group not receiving laboratory tests (range 19-64). The dermatologic diagnoses were about evenly distributed over the two groups and were classified into cutaneous vascular disease, diseases of the skin appendages (hair and sebaceous gland), eczematous disease, erythema or urticaria, infectious disease, papulosquamous disease, pigment anomalies, pruritus, and tumors. Table 1 details the subject characteristics.

\section{Reliability test of questionnaires}

Cronbach's $\alpha$ coefficients revealed that reliabilities of patients' responses exceed 0.70 , indicating an acceptable level of internal consistency.

\section{Comparison of the groups}

To compare the two independent groups (laboratory tests vs. no laboratory test), an independent $t$-test was conducted. The laboratory test group had a lower positive attitude toward doctors and less intention to follow doctor's recommendations as compared to the no laboratory test groups. However this difference was not significant (Table 2). In addition, the statistical testing revealed no significant differences in the patient's, 'authoritarian personality', 'mood', and 'intention to accept recommendations' between the two groups.

\section{Moderating effects of patient's personality}

Next, we investigated the effects of variables (laboratory tests vs. no laboratory test, high or low trust toward doctors, and high or low authoritarian personality) on patient attitude toward doctors and intention to accept their recommendations using two-way ANOVA. The groups (laboratory tests vs. no laboratory test) were divided into two groups based on the median value of two variables: trust toward doctors (cut-off value, 4.80) and authoritarian personality (cut-off value, 4.25).

According to the analysis of effects of trust toward doctors, the patients who trust doctors expressed a more positive attitude (3.90 vs. $4.79, p<0.001)$ and an increased intention to follow the doctor's recommendations $(4.28$ vs. $5.36, p<0.001)$ compared to patients that had less faith in their doctors. There was no relationship between trust in the doctor's recommendations and the receipt of laboratory tests (Table 3).

Table 1. Patient demographics.

\begin{tabular}{|lll|}
\hline & Laboratory test & $\begin{array}{l}\text { No laboratory } \\
\text { test }\end{array}$ \\
\hline $\mathrm{n} / \mathrm{N}(\%)$ & $50 / 100(50)$ & $50 / 100(50)$ \\
\hline $\mathrm{M} / \mathrm{F}$ ratio & $0.79(22 / 28)$ & $0.85(23 / 27)$ \\
\hline Mean age & $37.42(19-65)$ & $39.56(19-64)$ \\
\hline \multicolumn{1}{|c|}{ Diagnosis } & & \\
\hline Cutaneous vascular disease & 3 & 1 \\
\hline Diseases of the skin appendages & 5 & 8 \\
\hline Eczematous disease & 9 & 14 \\
\hline Erythema or urticaria & 19 & 20 \\
\hline Infectious disease & 9 & 3 \\
\hline Papulosquamous disease & 1 & 1 \\
\hline Pigment anomalies & 0 & 1 \\
\hline Pruritus & 2 & 0 \\
\hline Tumors & 2 & 2 \\
\hline
\end{tabular}


Table 2. Comparison between groups: results of the unpaired $t$-test (Lab, the laboratory test group; No Lab, no laboratory test group).

\begin{tabular}{|c|c|c|c|}
\hline Variables & Group & Mean & $p$-value \\
\hline \multirow{2}{*}{$\begin{array}{l}\text { Attitude toward doctor's } \\
\text { recommendations }\end{array}$} & Lab & 4.060 & \multirow{2}{*}{0.096} \\
\hline & No lab & 4.449 & \\
\hline \multirow{2}{*}{$\begin{array}{l}\text { Intention to follow doctor's } \\
\text { recommendations }\end{array}$} & Lab & 4.580 & \multirow{2}{*}{0.268} \\
\hline & No lab & 4.890 & \\
\hline \multirow{2}{*}{ Authoritarian personality } & Lab & 4.115 & \multirow{2}{*}{0.339} \\
\hline & No lab & 4.310 & \\
\hline \multirow{2}{*}{ Trust toward doctors } & Lab & 4.856 & \multirow{2}{*}{0.268} \\
\hline & No lab & 4.776 & \\
\hline \multirow{2}{*}{ Positive mood } & Lab & 3.614 & \multirow{2}{*}{0.189} \\
\hline & No lab & 3.426 & \\
\hline \multirow{2}{*}{ Negative mood } & Lab & 3.046 & \multirow{2}{*}{0.276} \\
\hline & No lab & 2.830 & \\
\hline
\end{tabular}

Analysis of the effects of having an authoritarian personality showed a significant effect of authoritarian personality on both the attitude toward doctor's recommendations, and the intention to follow the recommendations (Table 4). Patients with a more authoritarian personality were more positive toward the doctor's recommendations ( 3.99 vs. $4.65, p=0.01)$ and had a more intention to follow the recommendation ( 4.35 vs. $5.24, p=0.001)$. In addition, there was a significant relationship between authoritarian personality and laboratory tests (Table 4). For patients with a more authoritarian personality, laboratory tests decreased the intention to follow the recommendation (5.74 vs. $4.77, \mathrm{p}<0.05)$.

\section{Effects of gender and age}

Additionally, two-way ANOVA and correlation analysis were performed to evaluate variance by sex and age. Males had a more positive attitude toward the doctor's recommendations ( 4.72 vs. $3.92, p<0.05$ ) and more intention to follow the recommendations (5.06 vs. 4.47, $p<0.05$ ), as compared to females (Table 5). Also, measurements of authoritarian personality and trust in doctors were significantly higher in males (authority personality; 4.52 vs. 3.96, $p<0.01$, trust toward doctors; 5.04 vs. $4.64, p=0.05$ ). There was no interaction between sex and two personal traits on compliance $(p>0.1)$.

By correlation analysis, intention to follow the doctor's recommendations and trust toward the recommendation had a tendency to increase in older patients (correlation coefficient was 0.374 $(p<0.001)$ and $0.432(p<0.001)$, respectively (Table 6$)$.

\section{Discussion}

Compliance of a patient is 'the extent to which the patient's behavior matches agreed recommendation from the prescribers ${ }^{19}$. It is critical element in determining the beneficial effect of medical care and decided by interaction of multiple factors ${ }^{20,21}$. Many psychological models including Becker's health belief model have been introduced to explain compliance ${ }^{9}$. According to them, patients show increased compliance when they believe the threat of disease will be diminished by following health recommendations ${ }^{22}$. Also

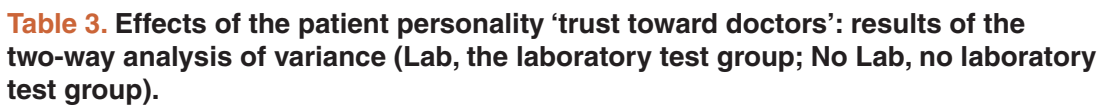

\begin{tabular}{|c|c|c|c|c|}
\hline \multirow[t]{2}{*}{ Independent variables } & \multicolumn{2}{|c|}{ Dependent variables } & \multirow{2}{*}{$\begin{array}{l}\text { Number of patients } \\
24\end{array}$} & \multirow{2}{*}{$\begin{array}{l}\text { Mean } \\
4.389\end{array}$} \\
\hline & \multirow{2}{*}{ Lab } & Higher trust $†$ & & \\
\hline \multirow{3}{*}{$\begin{array}{l}\text { Attitude toward doctor's } \\
\text { recommendations }\end{array}$} & & Lower trustł & 26 & 3.756 \\
\hline & \multirow{2}{*}{ No lab } & Higher trust & 18 & 5.315 \\
\hline & & Lower trust & 32 & 4.031 \\
\hline \multirow{4}{*}{$\begin{array}{l}\text { Intention to follow doctor's } \\
\text { recommendations }\end{array}$} & \multirow{2}{*}{ Lab } & Higher trust & 24 & 5.021 \\
\hline & & Lower trust & 26 & 4.173 \\
\hline & \multirow{2}{*}{ No lab } & Higher trust & 18 & 5.806 \\
\hline & & Lower trust & 32 & 4.375 \\
\hline & & & $p$-value & \\
\hline \multirow{3}{*}{$\begin{array}{l}\text { Attitude toward doctor's } \\
\text { recommendations }\end{array}$} & & Lab & 0.017 & \\
\hline & & Trust & $<0.001$ & \\
\hline & & Lab $\times$ trust & 0.189 & \\
\hline \multirow{3}{*}{$\begin{array}{l}\text { Intention to follow doctor's } \\
\text { recommendations }\end{array}$} & & Lab & 0.062 & \\
\hline & & Trust & $<0.001$ & \\
\hline & & Lab $\times$ trust & 0.268 & \\
\hline
\end{tabular}

$\dagger, \ddagger$ Measure of the 'Trust toward the doctors' divided into two groups by median value. 
Table 4. Effects of the patient personality 'authoritarian personality': results of the twoway analysis of variance (Lab, the laboratory test group; No Lab, no laboratory test group; autho, authority personality).

\begin{tabular}{|c|c|c|c|c|}
\hline Independent variables & \multicolumn{2}{|c|}{ Dependent variables } & Number of patients & Mean \\
\hline \multirow{4}{*}{$\begin{array}{l}\text { Attitude toward doctor's } \\
\text { recommendations }\end{array}$} & \multirow{2}{*}{$\mathrm{Lab}^{*}$} & Higher autho† & 22 & 4.515 \\
\hline & & Lower authoł & 28 & 3.702 \\
\hline & \multirow{2}{*}{ No lab** } & Higher autho & 21 & 4.794 \\
\hline & & Lower autho & 29 & 4.276 \\
\hline \multirow{4}{*}{$\begin{array}{l}\text { Intention to follow doctor's } \\
\text { recommendations }\end{array}$} & \multirow{2}{*}{ Lab } & Higher autho & 22 & 4.773 \\
\hline & & Lower autho & 28 & 4.429 \\
\hline & \multirow{2}{*}{ No lab } & Higher autho & 21 & 5.738 \\
\hline & & Lower autho & 29 & 4.276 \\
\hline & & & $p$-value & \\
\hline \multirow{3}{*}{$\begin{array}{l}\text { Attitude toward doctor's } \\
\text { recommendations }\end{array}$} & & Lab & 0.097 & \\
\hline & & Autho & 0.010 & \\
\hline & & Lab $\times$ autho & 0.563 & \\
\hline \multirow{3}{*}{$\begin{array}{l}\text { Intention to follow doctor's } \\
\text { recommendations }\end{array}$} & & Lab & 0.125 & \\
\hline & & Autho & 0.001 & \\
\hline & & Lab $\times$ autho & 0.036 & \\
\hline
\end{tabular}

$\dagger, \ddagger$ Measure of the 'Authoritarian personality' divided into two groups by median value.

Table 5. Effects of gender: results of the two-way analysis of variance.

\begin{tabular}{|c|c|c|c|c|}
\hline Independent variables & \multicolumn{2}{|c|}{ Dependent variables } & Number of patients & Mean \\
\hline \multirow{4}{*}{$\begin{array}{l}\text { Attitude toward doctor's } \\
\text { recommendations }\end{array}$} & \multirow{2}{*}{ Lab* } & Male & 22 & 4.409 \\
\hline & & Female & 28 & 3.786 \\
\hline & \multirow{2}{*}{ No lab** } & Male & 23 & 5.015 \\
\hline & & Female & 27 & 4.049 \\
\hline \multirow{4}{*}{$\begin{array}{l}\text { Intention to follow doctor's } \\
\text { recommendations }\end{array}$} & \multirow{2}{*}{ Lab } & Male & 22 & 4.750 \\
\hline & & Female & 28 & 4.446 \\
\hline & \multirow{2}{*}{ No lab } & Male & 23 & 5.348 \\
\hline & & Female & 27 & 4.500 \\
\hline & & & $p$-value & \\
\hline \multirow{3}{*}{$\begin{array}{l}\text { Attitude toward doctor's } \\
\text { recommendations }\end{array}$} & & Lab & 0.084 & \\
\hline & & Gender & 0.002 & \\
\hline & & Gender x lab & 0.494 & \\
\hline \multirow{3}{*}{$\begin{array}{l}\text { Intention to follow doctor's } \\
\text { recommendations }\end{array}$} & & Lab & 0.239 & \\
\hline & & Gender & 0.039 & \\
\hline & & Gender x lab & 0.325 & \\
\hline
\end{tabular}

* Laboratory test group.

${ }^{* *}$ No laboratory test group. 
Table 6. Effects of age: results of the correlation analysis.

\begin{tabular}{|llll|}
\hline & Mean & $\begin{array}{l}\text { Pearson correlation } \\
\text { coefficient }\end{array}$ & p-value \\
\hline Age & 38.490 & & \\
\hline $\begin{array}{l}\text { Attitude toward doctor's } \\
\text { recommendations }\end{array}$ & 4.277 & 0.374 & $<0.001$ \\
\hline $\begin{array}{l}\text { Intention to follow doctor's } \\
\text { recommendations }\end{array}$ & 4.735 & 0.432 & $<0.001$ \\
\hline
\end{tabular}

the doctor's attitude towards the patient, doctor's ability to bring out and respect the patient's concerns, ability to provide appropriate information, and ability to show empathy are important factors of compliance ${ }^{23}$.

Although the psychological aspects of patients and doctors have been emphasized in patient compliance, most of compliance studies in dermatology have focused on the diagnosis and treatment options as determining factors ${ }^{24-26}$. In 2010, Kim et al. ${ }^{8}$ first described the psychological impacts of skin biopsy, which is one of the most frequently performed diagnostic tools in dermatology. This study showed that skin biopsy subconsciously increase patients' positive attitude toward doctor's recommendations and potentially bias patients' decision for the treatment. This phenomenon was explained by terror management theory (TMT), which is generally studied in psychology and marketing, but also has been applied to medicine ${ }^{27}$. TMT states that people behave to protect themselves from fear of death when they are reminded of their own deaths. Societies traditionally have built cultural worldview (such as laws, cultures, and religions), and individuals adhere to these cultural worldview when confronting fear of mortality ${ }^{10}$. In medicine, certain health behaviors such as breast self-exam can subconsciously activate and facilitate people to remind death, and death act as conditioning behavior towards a longer life ${ }^{27}$.

In this study, we hypothesized that the laboratory tests, which are frequently recommended in dermatologic outpatient clinic, could be a stimulant of mortality salience because it reminds patients of more severe diseases or vital organ dysfunctions. Based on TMT, we expected that patients who had laboratory tests adhere to doctor's recommendations more than the patients who did not have laboratory tests.

Interestingly, the result of this study was contrary to our expectation. Although the differences between two groups were not statistically significant, the patients who had laboratory tests had tendency to show even lower positive attitude toward the doctor's recommendations and less intention to follow the recommendations. This suggests that laboratory tests do not subliminally increase the patient's fear of their disease or increase compliance.

Despite statistically insignificance in this study, no relationship between laboratory tests and adherence to doctors' recommendation raises important implications for future research. For example, biomarkers for guiding therapy selection and disease monitoring have been developed with skin biopsy in the field of dermatology ${ }^{28}$. However, skin biopsy has a risk of subliminally increase the patient's fear or anxiety and subconsciously bias patients' decision for the treatment ${ }^{8}$. On the other hand, laboratory tests such as blood test and urine test do not influence patient compliance and supply a neutral circumstance for patients' treatment decisions. Therefore, this study implicates that laboratory tests could be superior to skin biopsy as a source of biomarker development.

The limitation of this study is that we assessed patient compliance as a hypothetical construct and psychological concepts were examined using an indirect method. Also, the small sample size limited the statistical power of this study, and also the diagnosis of the participants and the types of treatments could not be randomized between groups.

We failed to prove our hypothesis based on TMT, but the results still have important implications in dermatologic outpatient clinics. The performance of laboratory tests does not seem to reinforce the patient's fear of their own disease, and instead possibly decreases lower the patient's trust in doctors. Doctors should not hesitate to perform laboratory tests when the situation requires this, but we suggest that careful consideration about possible psychological impacts is needed when ordering laboratory tests for patients. To enhance patient compliance with doctor's recommendations, doctors should carefully consider not only their diagnosis or treatment plan, but also the psychological impact of commonly performed tests and the patient's personality.

Data for Laboratory Tests and Compliance of Dermatologic Outpatients

1 widget/3 Data Files

http://dx.doi.org/10.6084/m9.figshare.805195

\section{Author contributions}

Won Ung Shin wrote the first draft of the article. Yoo Sang Baek edited the article, and reviewed the data. Tom Joonhwan Kim 
analyzed data, and interpreted results. Chil Hwan Oh interviewed the patients. Jaehwan Kim designed the study, edited the article, and has direct responsibility for the article.

\section{Competing interests}

No competing interests were disclosed.
Grant information

The author(s) declared that no grants were involved in supporting this work.

\section{Acknowledgement}

We thank Dr. Jung Woo Lee, Dr. Jae Woo Ahn, and Dr. Joo Ha Kim for critical comments on the manuscript.
1. Renzi C, Picardi A, Abeni D, et al:: Association of dissatisfaction with care and psychiatric morbidity with poor treatment compliance. Arch Dermatol. 2002; 138(3): 337-42.

PubMed Abstract | Publisher Full Text

2. Insel KC, Reminger SL, Hsiao CP: The negative association of independent personality and medication adherence. J Aging Health. 2006; 18(3): 407-18.

PubMed Abstract | Publisher Full Text

3. Axelsson $M$, Brink $E$, Lundgren J, et al: The influence of personality traits on reported adherence to medication in individuals with chronic disease: an epidemiological study in West Sweden. PLOS One. 2011; 6(3): e18241. PubMed Abstract | Publisher Full Text | Free Full Text

4. Bruce JM, Hancock LM, Arnett $P$, et al: Treatment adherence in multiple sclerosis: association with emotional status, personality, and cognition. J Behav Med. 2010; 33(3): 219-27. PubMed Abstract | Publisher Full Text

5. Hollo G, Kothy P, Geczy A, et al.: Personality traits, depression, and objectively measured adherence to once-daily prostaglandin analog medication in glaucoma. J Glaucoma. 2009; 18(4): 288-92. PubMed Abstract | Publisher Full Text

6. Augustin M, Holland B, Dartsch D, et al.: Adherence in the treatment of psoriasis: a systematic review. Dermatology. 2011; 222(4): 363-74. PubMed Abstract | Publisher Full Text

7. Miyachi $\mathrm{Y}$, Hayashi N, Furukawa F, et al:: Acne management in Japan: study of patient adherence. Dermatology. 2011; 223(2): 174-81.

PubMed Abstract | Publisher Full Text

8. $\mathrm{Kim} \mathrm{JH}$, Kim J, Jung $\mathrm{YH}$, et al.: Terror management theory in dermatology: skin biopsy influences patient compliance. Acta Derm Venereol. 2010 90(3): 246-50.

PubMed Abstract

9. Becker MH, Maiman LA: Sociobehavioral determinants of compliance with health and medical care recommendations. Med Care. 1975; 13(1): 10-24. PubMed Abstract | Publisher Full Text

10. Harmon-Jones E, Simon L, Greenberg J, et al: Terror management theory and self-esteem: evidence that increased self-esteem reduces mortality salience effects. J Pers Soc Psychol. 1997; 72(1): 24-36. PubMed Abstract | Publisher Full Text

11. Lieberman EJ: Terror management theory. Am J Psychiatry. 2004; 161(8): 1508; author reply-9. PubMed Abstract | Publisher Full Text

12. Simon L, Greenberg J, Harmon-Jones E, et al:: Terror management and cognitive-experiential self-theory: evidence that terror management occurs in the experiential system. J Pers Soc Psychol. 1997; 72(5): 1132-46. PubMed Abstract | Publisher Full Text

13. Anderson LA, Dedrick RF: Development of the Trust in Physician scale: a measure to assess interpersonal trust in patient-physician relationships. Psychol Rep. 1990; 67(3 Pt 2): 1091-1100. PubMed Abstract | Publisher Full Text

14. Kao AC, Green DC, Zaslavsky AM, et al.: The relationship between method of physician payment and patient trust. JAMA 1998; 280(19): 1708-14. PubMed Abstract | Publisher Full Text

15. Hoffman J: The Authoritarian Personality-Adorno TW, Frenkelbrunswik E, Levinson D, Sanford RN. Contemp Psychol. 1965; 10(11): 500.

16. Min K: Authoritarian personality and social prejudice among college students. Korean J Soc Psychol. 1989; 4: 146-68.

17. Watson D, Clark LA, Tellegen A: Development and validation of brief measures of positive and negative affect: the PANAS scales. J Pers Soc Psychol. 1988; 54(6): 1063-70.

PubMled Abstract | Publisher Full Text

18. Bobinski GS, Cox D, Cox A: Retail "sale" advertising, perceived retailer credibility, and price rationale. J Retailing. 1996; 72(3): 291-306. Publisher Full Text

19. Aronson JK: Compliance, concordance, adherence. Brit J Clin Pharmaco. 2007; 63(4): 383-4.

PubMed Abstract | Publisher Full Text | Free Full Text

20. Sherbourne CD, Hays RD, Ordway L, et al:: Antecedents of adherence to medical recommendations: results from the Medical Outcomes Study. J Behav Med. 1992; 15(5): 447-68.

PubMed Abstract | Publisher Full Text

21. Koberlein J, Kothe AC, Schaffert C: Determinants of patient compliance in allergic rhinoconjunctivitis. Curr Opin Allergy Clin Immunol. 2011; 11(3): 192-9. PubMed Abstract | Publisher Full Text

22. Vermeire $\mathrm{E}$, Hearnshaw $\mathrm{H}$, Van Royen $\mathrm{P}$, et al.: Patient adherence to treatment: three decades of research. A comprehensive review. J Clin Pharm Ther. 2001; 26(5): 331-42.

PubMed Abstract | Publisher Full Text

23. Rosenstock IM: Enhancing patient compliance with health recommendations. J Pediatr Health Care. 1988; 2(2): 67-72. PubMed Abstract | Publisher Full Text

24. Katsambas AD: Why and when the treatment of acne fails - What to do. Dermatology, 1998; 196(1): 158-61. PubMed Abstract | Publisher Full Text

25. Richards HL, Fortune DG, O'Sullivan TM, et al:: Patients with psoriasis and their compliance with medication. J Am Acad Dermatol. 1999; 41(4): 581-3. PubMed Abstract

26. van de Kerkhof PCM, de Hoop D, de Korte J, et al.: Patient compliance and disease management in the treatment of psoriasis in the Netherlands. Dermatology. 2000; 200(4): 292-8. PubMed Abstract | Publisher Full Text

27. Goldenberg JL, Arndt J: The implications of death for health: a terror management health model for behavioral health promotion. Psychol Rev. 2008; 115(4): 1032-53. PubMed Abstract | Publisher Full Text

28. Zaba LC, Suárez-Fariñas M, Fuentes-Duculan J, et al: Effective treatment of psoriasis with etanercept is linked to suppression of IL-17 signaling, not immediate response TNF genes. J Allergy Clin Immunol. 2009; 124(5): 1022-10.e1-395.

PubMed Abstract | Publisher Full Text | Free Full Text 


\section{Open Peer Review}

\section{Current Peer Review Status:}

\section{Version 1}

Reviewer Report 01 November 2013

https://doi.org/10.5256/f1000research.2244.r2291

(C) 2013 Arenas R. This is an open access peer review report distributed under the terms of the Creative Commons Attribution License, which permits unrestricted use, distribution, and reproduction in any medium, provided the original work is properly cited.

\section{Roberto Arenas}

Departamento of Dermatology, Hospital General Dr Manuel Gea Gonzalez, Tlalpan, DF 14000, Mexico

This article is interesting, practical and useful

Competing Interests: No competing interests were disclosed.

I confirm that I have read this submission and believe that I have an appropriate level of expertise to confirm that it is of an acceptable scientific standard.

Reviewer Report 28 October 2013

\section{https://doi.org/10.5256/f1000research.2244.r2020}

(C) 2013 Abdel-Naser M. This is an open access peer review report distributed under the terms of the Creative Commons Attribution License, which permits unrestricted use, distribution, and reproduction in any medium, provided the original work is properly cited.

\section{Mohamed Badawy Hassan Tawfik Abdel-Naser}

Department of Dermatology and Venereology, Ain Shams University, Cairo, Egypt

The manuscript is well written and informative. However, there some remarks in the following sections that could be be taken into consideration:

\section{Introduction:}

"In a dermatologic clinic, laboratory tests such as blood and urine tests are one of the main examinations" Is it better to use "investigations" or "analyses" instead of repeating the word "tests" likewise the second "the cultural worldviews" can be replaced by "them"

"..blood urea nitrogen analysis, and creatinine analysis." is it fine with "blood urea nitrogen and 


\section{Survey:}

creatinine analyses"

"towards" and "toward" are both used in the whole manuscript. You may adhere to one or same spelling

\section{Trust toward doctors:}

“..believe that doctors perform: 1. Perform only medically necessary..." you may delete the first "perform".

"In case of fourth state reverse scale was used, and average of patients' scale to these five questions was used" please revise this statement.

Authoritarian personality:

"..amount of trust towards doctors, might influences" consider "might influence"

"..the scale consist" consider "the scale consists"

Reliability test of questionnaires:

"Cronbach's a coefficients" this statistical method has not been mentioned or referred to in the statistics section

\section{Comparison of the groups:}

"..an independent $t$-test" is it equivalent to unpaired t test that has been mentioned in the statistics section? You should adhere to the same terminology.

Moderating effects of patient's personality:

"The patients who trust doctors expressed a more positive attitude (3.90 vs. 4.79, $p<0.001)$ " Please check these values with those in the table for errors. This is also applicable to all values mentioned in the text with their corresponding values in the tables. Also the

\section{Discussion:} arrangement of the values (higher values and then the lower).

"...skin biopsy subconsciously increase patients" consider "increases" also in other locations in the section.

"..and death act as conditioning" consider "acts"

"Despite statistically insignificance in this study, no relationship between laboratory tests and adherence to doctors' recommendation raises important implications for future research" Please revise this statement

"..instead possibly decreases lower the patient's trust in doctors" please revise the statement

Competing Interests: No competing interests were disclosed.

I confirm that I have read this submission and believe that I have an appropriate level of expertise to confirm that it is of an acceptable scientific standard. 
The benefits of publishing with F1000Research:

- Your article is published within days, with no editorial bias

- You can publish traditional articles, null/negative results, case reports, data notes and more

- The peer review process is transparent and collaborative

- Your article is indexed in PubMed after passing peer review

- Dedicated customer support at every stage

For pre-submission enquiries, contact research@f1000.com 